tendentsii i perspektivy razvitiia. Ezhegodnik. Vol. 11 / ed. by V. I. Gerasimov and D. V. Efremenko. Moscow, RAN INION. Pp. 198-200. (In Russ.).

Submission date: 15.08.2017.

Крылова Ирина Анатольевна - доктор философских наук, ведущий научный сотрудник сектора философских проблем политики Института философии Российской академии наук. Aдрес: 109240, Россия, г. Москва, ул. Гончарная, д. 12, стр. 1. Тел.: +7 (495) 697-91-89. Эл. адрес: tatyanawings@gmail.com

Krylova Irina Anatolievna, Doctor of Philosophy, Leading Research Fellow, Department of the Philosophical Problems of Politics, Institute of Philosophy, Russian Academy of Sciences. Postal address: 12, Bld. 1, Goncharnaya St., Moscow, Russian Federation 109240. Tel.: +7 (495) 697-91-89. E-mail: tatyanawings@gmail.com

DOI: $10.17805 / z p u .2017 .4 .17$

\title{
Актуальность количественной оценки качества прямого взаимодействия граждан и власти
}

\author{
П. А. КОРОтКОв, О. А. МАТВеЕВА, О. Е. РЫЖАКОВА \\ ПОВОЛЖСКИЙ ГОСУДАРСТВЕННЫЙ ТЕХНОЛОГИЧЕСКИЙ УНИВЕРСИТЕТ, \\ E. А. ЗАГАЙНОВА \\ КАЗАНСКИЙ (ПРИВОЛЖСКИЙ) ФЕДЕРАЛЬНЫЙ УНИВЕРСИТЕТ
}

В статье исследуется проблема количественной оценки качества прямого взаимодействия граждан и власти. Показано, что традиционная форма диалога гражданского общества и власти не удовлетворяет рядовых граждан, которые предпочитают обращаться к представителям власти напрямую посредством наиболее массового канала коммуникации - института обращений граждан - и прямых линий с Президентом России. Это определяет необходимость разработки количественных подходов к оценке и анализу динамики качества прямого взаимодействия граждан и власти, осуществляемого посредством обращений граждан, на региональном уровне, как наиболее приближенном к населению. Формулируются понятия взаимодействия и качества взаимодействия граждан и власти. Указываются правовые основы обращений граждан в органы власти. Анализируются обзоры обращений граждан, размещенные на официальных сайтах высших исполнительных органов государственной власти субъектов РФ. Установлено, что данные обзоры значительно различаются по объему и полноте представленной информации, а применяемые в них количественные методы направлены прежде всего на анализ тематики обращений. Показано, что наличие статистических данных, содержащихся в обзорах обращений граждан, позволяет конструировать различные показатели качества и эффективности деятельности органов власти. При этом необходимо иметь в виду, что сухие цифры, как правило, не интересны гражданам, а без внимания со стороны общества власть зачастую игнорирует эти показатели.

Предлагается построить индекс качества взаимодействия граждан и власти на основе показателя повторности обращений граждан в высшие исполнительные органы государственной власти субъектов РФ с последующим построением рейтинга администраций регионов. Рейтинг администраций регионов предлагается разбить на три группы с использованием порядковых статистик, поскольку данные статистики являются устойчивыми к наличию статистических «выбросов» в выборке. Для превращения индекса 
качества взаимодействия граждан и власти в инструмент воздействия на власть предлагается присвоить эмоционально окрашенные наименования выделенным группам администраций регионов, например «нормальные», или «адекватные», «отзывчивые» и «нерадивые».

Заключается, что предлагаемые количественные оценки качества взаимодействия граждан и власти на региональном уровне могут использоваться в качестве информационной поддержки для принятия более обоснованных управленческих решений, направленных на повышение качества диалога граждан и власти, формирующих доверие к власти и обеспечивающих социальный порядок.

Ключевые слова: власть; граждане; взаимодействие; качество взаимодействия; оценивание; количественная оценка

\section{ВВЕАЕНИЕ}

Традиционной формой диалога гражданского общества и власти является деятельность ассоциаций граждан: общественных организаций, объединений и иных негосударственных некоммерческих организаций. В России площадки для диалога общества и власти представлены Общероссийским народным фронтом, Общественной палатой, общественными советами при органах государственной власти, экспертными советами, региональными общественными палатами и др. Предполагается, что диалог общества и власти должен постоянно развиваться и перемещаться на региональный и местный уровни, как наиболее приближенные к населению (Взаимодействие общества ..., 2017: Электронный ресурс).

Оценивая качество диалога общества и власти в России, представители «третьего сектора» высказывают оценочные суждения типа: «Сейчас качество этого диалога очень низкое...» (цит. по: Акопов, 2014: Электронный ресурс). Комментируя массовые уличные протесты, представители высших органов государственной власти высказывают аналогичное мнение и выдвигают предложения по созданию широких площадок Аля диалога с разными слоями общества (Матвиенко поручила ..., 2017: Электронный ресурс).

Вместе с тем роль площадок для диалога, суть общественных организаций и объединений не всегда ясны рядовым гражданам, представления об общих интересах и целях зачастую не совпадают, что вкупе с развитием информационных технологий формирует повышенный интерес граждан к прямому диалогу с властью, минуя традиционных посредников. Об этом убедительно свидетельствуют прямые линии Президента с гражданами России, во время которых главе государства приходится заниматься проблемами, которые могли быть решены на региональном и муниципальном уровнях.

Следует отметить, что государство предлагает более доступные и, казалось бы, әффективные инструменты прямого взаимодействия граждан и власти, например институт обращений граждан во властные структуры. Однако результаты тех же прямых линий с Президентом ставят вопрос об эффективности данного института на уровне отдельных регионов и страны в целом, а более половины граждан, согласно опросам общественного мнения, утверждают, что эффективных способов воздействия на власть нет (Караткевич, 2016: Электронный ресурс). Это определяет необходимость разработки подходов к оценке и анализу динамики качества прямого взаимодействия граждан и власти, особенно на региональном уровне, наиболее приближенном к населению, которые одновременно должны стать инструментом воздействия на власть. 
Объект исследования - качество взаимодействия граждан и власти, осуществляемого посредством института обращений граждан во властные структуры, на уровне высших исполнительных органов государственной власти субъектов РФ.

Предмет исследования - количественные методы оценки качества взаимодействия граждан и власти, осуществляемого посредством института обращений граждан во властные структуры, на уровне высших исполнительных органов государственной власти субъектов РФ.

Научная новизна исследования заключается в следующем: впервые в отечественной науке предложено применять на систематической основе статистические данные повторных и многократных обращений граждан для количественной оценки качества взаимодействия граждан и высших исполнительных органов государственной власти субъектов РФ, которые традиционно применялись в естественных науках, например в медицине, и в практике работы колл-центров; обосновано введение эмоционально окрашенных наименований градаций шкалы оценок качества взаимодействия граждан и высших исполнительных органов государственной власти субъектов РФ, обеспечивающих эмоционально заинтересованное отношение граждан и власти к полученным оценкам и побуждающих представителей власти к принятию мер по повышению качества взаимодействия.

\section{ОСНОВНЫЕ ПОНЯТИЯ И ИСТОЧНИКИ ААННЫХ}

Взаимодействие граждан и власти в контексте исследования рассматривается как обмен информацией и действиями между гражданами и властью посредством института обращений, направленный прежде всего на решение вопросов, затрагивающих индивидуальные и коллективные интересы граждан.

Качество взаимодействия граждан и власти характеризует его способность вызывать удовлетворяющие граждан ответные действия власти.

Институт обращений граждан во властные структуры закреплен законодательно в Конституции Российской Федерации, в федеральных законах, в том числе в Федеральном законе от 6 октября 2003 г. № 131-Ф3 «Об общих принципах организации местного самоуправления в Российской Федерации», Федеральном законе от 2 мая 2006 г. №59-Ф3 «О порядке рассмотрения обращений граждан Российской Федерации».

Официальные сайты органов государственной власти и местного самоуправления содержат раздел «Обращения граждан», в котором размещаются периодические обзоры обращений граждан, включающие статистические данные и качественно-количественный анализ обращений. Аанные обзоры значительно различаются по объему и полноте представленной информации, что связано с отсутствием единых требований к их содержанию.

Наиболее объемные (более 500 с.) и содержательные типы обзоров (периодические, оперативные, информационные, информационно-статистические, информационно-аналитические, тематические) представлены на сайте Управления Президента России по работе с обращениями граждан и организаций (Обзоры обращений: Электронный ресурс). В этих обзорах в той или иной степени используются количественные методы преимущественно для анализа структуры взаимодействия и тематики обращений граждан с целью выявления приоритетных проблем, волнующих население.

Вместе с тем наличие статистических данных, содержащихся в обзорах обращений граждан, позволяет конструировать различные показатели качества и эффективно- 
сти деятельности органов власти. Например, О. А. Калашникова предлагает рассматривать количество обращений, направленных в органы власти по вопросам, не соответствующим их компетенции, как показатель качества муниципального управления (Калашникова, 2009).

При разработке показателей качества и эффективности деятельности органов власти необходимо иметь в виду, что сухие цифры, как правило, не интересны гражданам, а без внимания со стороны общества власть зачастую игнорирует эти показатели. В свою очередь, эмоционально окрашенные наименования оценок привлекают внимание всех заинтересованных сторон, мотивируя власть предпринимать меры, направленные на повышение качества и эффективности деятельности. Не случайно даже Президент России зачастую употребляет образные выражения, обладающие повышенным эмоционально-экспрессивным фоном, привлекающие внимание населения (Седых, 2016). Так, в ходе прямой линии 2013 г., отвечая на вопрос жительницы Омска, он назвал мәра «поросенком» (Путин назвал ..., 2013: Электронный ресурс).

\section{ИНАЕКС КАЧЕСТВА ВЗАИМОАЕЙСТВИЯ ГРАЖААН И ВААСТИ}

На наш взгляд, значительным потенциалом при оценке качества взаимодействия граждан и власти обладают показатели повторности обращений по тем же самым вопросам.

Аействительно, в естественных науках, например в медицине, широко используются показатели повторности обращений в поликлинику, повторности госпитализации, удельного веса повторных вызовов, которые характеризуют эффективность диспансеризации больных с хроническим заболеваниями, качество стационарной помощи, качество работы бригад скорой медицинской помощи и др. (Методические рекомендации ..., 2005).

Оценка эффективности контакт-центров основана на использовании показателя успешного решения вопросов при первом обращении, обратного показателю повторности обращений (Голубев, 2012: Электронный ресурс).

Несмотря на то что показатели повторности обращений, как правило, содержатся в обзорах обращений граждан, при анализе им не уделяется должного внимания. Повидимому, это связано с тем, что ст. 5 Федерального закона от 2 мая 2006 г. № 59-Ф3 «О порядке рассмотрения обращений граждан Российской Федерации» при определенных условиях позволяет должностному лицу либо уполномоченному на то лицу принять решение о безосновательности очередного обращения и прекращении переписки с гражданином по данному вопросу. Аругими словами, повторные обращения граждан при необходимости могут интерпретироваться как проявления необоснованного упрямства, на которые вполне законно можно не обращать внимания.

Между тем наличие повторных обращений в органы власти независимо от их причин (отсутствие исчерпывающих и полных разъяснений на поставленные вопросы, невыполнение ранее данных обещаний, невозможность решения вопросов в связи с отсутствием финансирования и др.) означает, что ответные действия власти не удовлетворяют граждан. Следовательно, рост доли повторных обращений однозначно свидетельствует о снижении качества взаимодействия граждан и власти.

Указанные соображения позволяют построить индекс качества взаимодействия граждан и власти, который может быть рассчитан по формуле

$$
I_{i, j}=1-\left(\frac{n_{i, j}}{N_{i, j}}\right),
$$


где $I i, j-$ индекс качества взаимодействия граждан и высшего исполнительного органа государственной власти $i$-го субъекта РФ в течение $j$-го года; $n_{i, j}-$ количество повторных обращений граждан в высший исполнительной орган государственной власти $i$-го субъекта РФ в течение $j$-го года; $N_{i, j}-$ количество всех (первичных и повторных) обращений граждан в высший исполнительной орган государственной власти $i$-го субъекта РФ в течение $j$-го года.

Индекс $I i, j$ может принимать значения от 0 до 1 , где 0 соответствует самому низкому качеству взаимодействия граждан и высшего исполнительного органа государственной власти субъекта РФ, а 1 - самому высокому.

Поскольку единой базы данных по обращениям граждан в региональные органы власти не существует, то в качестве источников исходных данных могут использоваться обзоры обращений граждан, размещенные в открытом доступе на официальных сайтах высших исполнительных органов государственной власти субъектов РФ. При этом перечень изучаемых администраций регионов формируется эндогенно, т. е. в процессе сбора исходных данных в выборку попадают лишь те администрации регионов, на сайтах которых публикуются годовые данные о количестве повторных обращений. Количество анализируемых лет также зависит от представленности исходных данных.

\section{ПЕРСПЕКТИВЫ ИСПОАЬЗОВАНИЯ ИНАЕКСА КАЧЕСТВА ВЗАИМОАЕЙСТВИЯ ГРАЖААН И ВААСТИ}

По значениям полученного индекса можно строить рейтинги высших исполнительных органов государственной власти субъектов РФ, позволяющие определить место администрации региона в рейтинге относительно администраций других регионов.

Рейтинг предлагается разбить на три группы с использованием порядковых статистик - квартилей - в качестве критериальных значений $\left(\mathrm{I}^{1} / 4-\right.$ верхняя квартиль значение индекса, выше которого находится 25\% администраций регионов; М - медиана - значение индекса, выше которого находится 50\% администраций регионов, и I $3 / 4$ - нижняя квартиль - значение индекса, выше которого находится $75 \%$ администраций регионов).

Использование порядковых статистик (квартилей, медианы) позволит более объективно оценить распределение высших исполнительных органов государственной власти субъектов РФ по значениям индекса качества взаимодействия граждан и власти, поскольку данные статистики являются устойчивыми к наличию статистических «выбросов» в выборке.

Аля превращения индекса качества взаимодействия граждан и власти в инструмент воздействия на власть предлагается присвоить эмоционально окрашенные наименования выделенным группам администраций регионов. Так, администрации регионов, имеющих значения индекса $I i, j$, расположенные в 25-75\%-ной зоне выборки, можно рассматривать как «нормальные», или «адекватные». Администрации регионов, имеющие значения выше границы $\mathrm{I}^{1 / 4}$, находятся в числе $25 \%$ лучших и могут получить эмоционально оценочное наименование «отзывчивые». Особое внимание к организации более качественного взаимодействия граждан и власти должны обратить администрации регионов со значениями индекса, расположенными ниже I3/4, выше которых находятся 75\% администраций регионов. Такие администрации регионов могут быть названы «нерадивыми». 
Аля выявления высших исполнительных органов государственной власти субъектов РФ, имеющих проблемы с обеспечением качества взаимодействия граждан и власти, необходимо провести анализ динамики индекса $I i, j$, например, с использованием двухфакторного дисперсионного анализа с одним наблюдением в ячейке.

Прежде чем переходить к анализу динамики индекса $I i, j$, необходимо провести качественную верификацию построенного рейтинга и оценку его устойчивости. Качественная верификация рейтинга может проводиться путем оценки его согласованности (непротиворечивости) с рейтингами регионов, представленными, например, на сайте автоматизированной информационной системы «Мониторинг государственных сайтов» (https://gosmonitor.ru/). Оценка устойчивости рейтинга может проводиться с использованием модифицированного алгоритма (Коротков и др., 2015).

\section{ЗАКАЮЧЕНИЕ}

Качество взаимодействия граждан и власти, как правило, оценивается с использованием неоднозначных экспертных оценок представителей уполномоченных органов власти, общественных организаций и объединений, на основании которых делаются выводы о необходимости развития тех или иных площадок для диалога. При этом органы власти, особенно на уровне регионов, зачастую игнорируют экспертные оценки представителей гражданского общества, ссылаясь на их субъективность, а рядовые граждане, по существу, не отождествляют себя с какими-либо объединениями, предпочитая обращаться в органы власти напрямую.

Обеспечить прямое взаимодействие граждан и власти призван институт обращений. В отличие от исследований института обращений граждан, в которых главным образом изучается нормативно-правовой (юридический) аспект, данная работа направлена на изучение информационного и коммуникативно-управленческого аспектов.

Предлагается оценивать качество взаимодействия граждан и власти в регионах и его динамику на основе индекса качества взаимодействия граждан и высших исполнительных органов государственной власти субъектов РФ, построенного с использованием показателя повторности обращений. Новизна заключается в систематическом применении данных повторных и многократных обращений граждан для количественной оценки качества взаимодействия граждан и власти, а также во введении эмоционально окрашенных наименований градаций индекса, обеспечивающих повышенные интерес и внимание к индексу со стороны граждан и власти, мотивирующих власть к принятию мер по повышению качества взаимодействия с гражданами.

Полученные количественные оценки, наряду с существующими качественными оценками, могут использоваться как информационная поддержка для принятия более обоснованных управленческих решений, направленных на повышение качества диалога граждан и власти, формирующих доверие к власти и обеспечивающих в конечном счете социальный порядок.

\section{СПИСОК АИТЕРАТУРЫ}

Акопов, П. (2014) У Народного фронта получается создавать конкуренцию на внутриполитической арене [Электронный ресурс] // Взгляд. 30 декабря. URL: https://vz.ru/politics/2014/ 12/30/722295.print.html (дата обращения: 24.05.2017).

Голубев, В. (2012) Пять основных элементов успешной программы оценки FCR [Электронный ресурс]// Статьи CallCenterGuru. 28 апреля. URL: https://callcenterguru.ru/blogs/articles/ 2012/04/28/ (дата обращения: 24.05.2017). 
Калашникова, О. А. (2009) Проблемы взаимоотношений региональных и муниципальных органов власти в контексте реформирования системы местного самоуправления (на материалах Краснодарского края) // Человек. Сообщество. Управление. № 2. С. 49-60.

Караткевич, А. Г. (2016) Ценности свободы и демократии в политической культуре российского общества [Электронный ресурс] // Информационный гуманитарный портал «Знание. Понимание. Умение». №6. URL: http://www.zpu-journal.ru/e-zpu/2016/6/Karatkevich_Values/ index.php?sphrase_id=206423 (дата обращения: 24.05.2017).

Коротков, П. А., Трубянов, А. Б., Загайнова, Е. А., Никоноров, К. Н. (2015) Анализ устойчивости оценок экологической эффективности крупных городов [Электронный ресурс]// Фундаментальные исследования. № 11 (4). С. 793-797. URL: https://fundamental-research.ru/ru/article/view?id=39510 (дата обращения: 24.05.2017).

Матвиенко поручила сенаторам найти площадки для широкого диалога власти и общества (2017) [Электронный ресурс]// TACC. 29 марта. URL: http://tass.ru/politika/4134442 (дата обращения: 24.05.2017).

Методические рекомендации по статистическому анализу показателей здоровья и деятельности организаций здравоохранения (2005) / сост. В. А. Медик и др. Великий Новгород: Институт медицинского образования НовГУ им. Ярослава Мудрого. 65 с.

Обзоры обращений [Электронный ресурс]// Управление Президента по работе с обращениями граждан и организаций. URL: http://letters.kremlin.ru/digests (дата обращения: 24.05.2017).

Путин назвал «поросенком» мэра Омска (2013) [Электронный ресурс] // ИA REGNUM. 25 апреля. URL: https://regnum.ru/news/1653101.html (дата обращения: 24.05.2017).

Седых, А. П. Кто сильнее? Анализ политических речей Путина и Меркель (2016) [Электронный ресурс] // Переселенческий Вестник. 20 октября. URL: https://www.aussiedlerbote. $\mathrm{de} / \mathrm{main} / 1060$-kto-silnee-analiz-politicheskih-rechey-putina-i-merkel.html (дата обращения: 24.05.2017).

Aата поступления: 05.06.2017 2.

\author{
RELEVANCE OF THE QUANTITATIVE ASSESSMENT OF THE QUALITY \\ OF DIRECT INTERACTION BETWEEN CITIZENS AND AUTHORITIES \\ P. A. Korotkov, O. A. Matveeva, O. E. Ryzhakova \\ Volga STATE UNIVERSITY OF TECHNOLOGY,
}

\title{
E. A. ZAGAYNOVA \\ KAZAN FEDERAL UNIVERSITY
}

The article examines the problem of quantitative assessment of the quality of direct interaction between citizens and authorities. It is shown that the traditional form of the dialogue between civil society and the authorities does not satisfy ordinary citizens who prefer to appeal directly to representatives of the authorities through the institute of citizens' appeals, which is considered to be the most mass communication channel, and through direct lines with the President of Russia. It determines the necessity to develop quantitative approaches to the assessment and analysis of the dynamics of the quality of direct interaction between citizens and authorities, implemented through citizens' appeals at the regional level as the closest to the population.

The concepts of interaction and the quality of interaction between citizens and authorities are formulated. The legal basis for citizens' appeals to the authorities is indicated. The paper analyses reviews of citizens' appeals, posted on the official websites of the highest executive bodies of state power of the constituent entities of the Russian Federation. It is stated that these reviews differ significantly in the volume and completeness of the information presented, and the quantitative methods which are used in such reviews are aimed primarily at analysing the subject matter of appeals. It is shown that the availability of statistical data, which the reviews of citizens' appeals contain, makes it possible to construct various indicators of the quality and efficiency of government activities. It should be kept in 
mind that, as a rule, dry figures are generally of no interest to citizens and the authorities often ignore these figures if left without public attention.

The authors suggest developing an index of the quality of interaction between citizens and authorities on the basis of the index of the repeatability of citizens' appeals to the highest executive bodies of state power of the constituent entities of the Russian Federation with the subsequent compiling of the ranking of regional administrations. The regional administrations' ranking is proposed to be divided into three groups using ordinal statistics, since the statistical data are resistant to the presence of statistical "emissions" in the sample. To transform the index of the quality of interaction between citizens and government into the instrument for influencing the authorities, it is proposed to assign emotionally coloured names to the selected groups of regional administrations, for example: "normal", or "adequate", "responsive" and "neglectful".

It is concluded that the proposed quantitative assessment of the quality of interaction between citizens and authorities at the regional level can be used as the information support for making more validated and solid managerial decisions aimed at improving the quality of dialogue between citizens and authorities that build trust in power and ensure social order.

Keywords: power; citizens; interaction; quality of interaction; evaluation; quantitative assessment

\section{REFERENCES}

Akopov, P. (2014) U Narodnogo fronta poluchaetsia sozdavat' konkurentsiiu na vnutripoliticheskoi arene. Vz.ru. December 30 [online] Available at: https://vz.ru/politics/2014/12/30/722295. print.html (accessed: 24.05.2017). (In Russ.).

Golubev, V. (2012) Piat' osnovnykh elementov uspeshnoi programmy otsenki FCR. CALLCENTERGURU. April 28 [online] Available at: https://callcenterguru.ru/blogs/articles/2012/04/28/ (accessed: 24.05.2017). (In Russ.).

Kalashnikova, O. A. (2009) Problemy vzaimootnoshenii regional'nykh i munitsipal'nykh organov vlasti v kontekste reformirovaniia sistemy mestnogo samoupravleniia (na materialakh Krasnodarskogo kraia). Chelovek. Soobshchestvo. Upravlenie, no. 2, pp. 49-60. (In Russ.).

Karatkevich, A. G. (2016) Tsennosti svobody i demokratii v politicheskoi kul'ture rossiiskogo obshchestva. Informatsionnyi gumanitarnyi portal "Znanie. Ponimanie. Umenie”, no. 6 [online] Available at: http://www.zpu-journal.ru/e-zpu/2016/6/Karatkevich_Values/index.php?sphrase_ $\mathrm{id}=206423$ (accessed: 24.05.2017). (In Russ.).

Korotkov, P. A., Trubianov, A. B., Zagainova, E. A. and Nikonorov, K. N. (2015) Analiz ustoichivosti otsenok ekologicheskoi effektivnosti krupnykh gorodov. Fundamental'nye issledovaniia, no. 11 (4), pp. 793-797 [online] Available at: https://fundamental-research.ru/ru/article/view?id $=39510$ (accessed: 24.05.2017). (In Russ.).

Matvienko poruchila senatoram naiti ploshchadki dlia shirokogo dialoga vlasti i obshchestva (2017). TASS, March 29 [online] Available at: http://tass.ru/politika/4134442 (accessed: 24.05.2017). (In Russ.).

Metodicheskie rekomendatsii po statisticheskomu analizu pokazatelei zdorov'ia $i$ deiatel'nosti organizatsii zdravookbraneniia (2005)/ comp. by V. A. Medik at al. Velikii Novgorod, Institut meditsinskogo obrazovaniia NovGU im. Iaroslava Mudrogo. 65 p. (In Russ.).

Obzory obrashchenii. Upravlenie Prezidenta po rabote s obrashcheniiami grazbdan i organizatsii [online] Available at: http://letters.kremlin.ru/digests [archived in WebCite] (accessed: 24.05.2017). (In Russ.).

Putin nazval "porosenkom" mera Omska (2013). IA REGNUM. April 25 [online] Available at: // https://regnum.ru/news/1653101.html [archived in WebCite] (accessed: 24.05.2017). (In Russ.).

Sedykh, A. P. Kto sil'nee? Analiz politicheskikh rechei Putina i Merkel' (2016). Pereselencheskii Vestnik (Zeitung "Aussiedlerbote"). October 20 [online] Available at: https://www.aussiedlerbote.de/main/1060-kto-silnee-analiz-politicheskih-rechey-putina-i-merkel.html (accessed: 24.05.2017). 
Коротков Петр Анатольевич - кандидат экономических наук, доцент кафедры транспортно-технологических машин Поволжского государственного технологического университета, член Российской ассоциации статистиков. Адрес: 424000, Россия, г. Йошкар-Ола, пл. Аенина, А. 3. Тел.:+7 (8362)68-68-86. Эл. aареc: korotkovpa@volgatech.net, korotp@bk.ru

Матвеева Оксана Александровна - старший преподаватель кафедры иностранных языков и лингвистики Поволжского государственного технологического университета. Адрес: 424000, Россия, г. Йошкар-Ола, пл. Аенина, д. 3. Тел.: +7 (8362) 68-60-41. Эл. адрес: matveevao@volgatech.net

Рыжакова Ольга Евгеньевна - аспирант кафедры прикладной математики и информационных технологий Поволжского государственного технологического университета. Адрес: 424000, Россия, г. Йошкар-Ола, пл. Иенина, д. 3. Тел.: +7 (8362) 68-68-55. Эл. адрес: olgaryzh@ yandex.ru

Загайнова Екатерина Андреевна - студент магистерской программы «Аудит и финансовый менеджмент» Казанского (Приволжского) федерального университета. Адрес: 420008, Россия, г. Казань, ул. Кремлевская, А. 18. Тел.: +7 (843) 2-911-398. Эл. алрес: katenazag@yandex.ru

Korotkov Pyotr Anatolievich, Candidate of Economics, Associate Professor, Department of Transport and Technological Machines, Volga State University of Technology; Member, Russian Association of Statisticians. Postal address: 3, Lenina Sq., Yoshkar-Ola, Russian Federation 424000. Tel./fax:+7 (8362)68-68-86. E-mail: korotkovpa@volgatech.net, korotp@bk.ru

Matveeva Oksana Aleksandrovna, Senior Lecturer, Department of Foreign Languages and Linguistics, Volga State University of Technology. Postal address: 3, Lenina Sq., Yoshkar-Ola, Russian Federation 424000. Tel./fax: +7 (8362) 68-60-41. E-mail: matveevao@volgatech.net

Ryzhakova Olga Evgenievna, Postgraduate Student, Department of Applied Mathematics and Informatics, Volga State University of Technology. Postal address: 3, Lenina Sq., Yoshkar-Ola, Russian Federation 424000. Tel./fax: +7 (8362) 68-68-55. E-mail: olgaryzh@yandex.ru

Zagaynova Ekaterina Andreevna, Graduate Student, "Audit and Finance Management" degree programme, Kazan Federal University. Postal address: 18, Kremlyovskaya St., Kazan, Russian Federation 420008. Tel./fax: +7 (843) 2-911-398. E-mail: katenazag@yandex.ru 